\title{
Obtaining funding an age-old problem for young researchers with novel ideas
}

\author{
n Cite as: CMAJ 2018 April 23;190:E516-7. doi: 10.1503/cmaj.109-5583
}

Posted on cmajnews.com on Apr. 4, 2018.

W ith the infusion of billions into scientific research in the 2018 budget, the government is promising to support young researchers. But young scientists with novel ideas will likely still face challenges. It's an age-old problem, as the University of Toronto's Dr. Warren Lee can attest.

A critical care specialist, Lee was at Toronto's St. Michael's Hospital during the $2009 \mathrm{H} 1 \mathrm{~N} 1$ pandemic, looking after young patients in intensive care with the flu and severe respiratory failure. He had completed his doctorate in cell biology a few years earlier and he thought the root of their problems could be the flu virus damaging the lung endothelium and causing lung edema. Lee wondered if guarding the endothelium could be a novel way to treat patients, so he applied for a grant to study the effects of influenza on endothelial cells.

"I got really scathing reviews, saying I was studying the wrong thing - I shouldn't be studying the lung endothelium because [flu] doesn't affect the endothelium," he recalled. "It was a very tough slog at first."

For basic science, the Canadian Institutes of Health Research (CIHR) was the only game in town, and it turned Lee down for funding three years in a row. "If you submit a grant on influenza, even if it's influenza-induced lung injury, it goes to people who are experts on influenza," he said. "And they may have no interest and no knowledge of lung injury or lung edema."

Other young scientists shared similar stories of repeated rejection with the panel that authored a report for Canada's 2017 fundamental science review (the Naylor Report). "The situation is untenable and

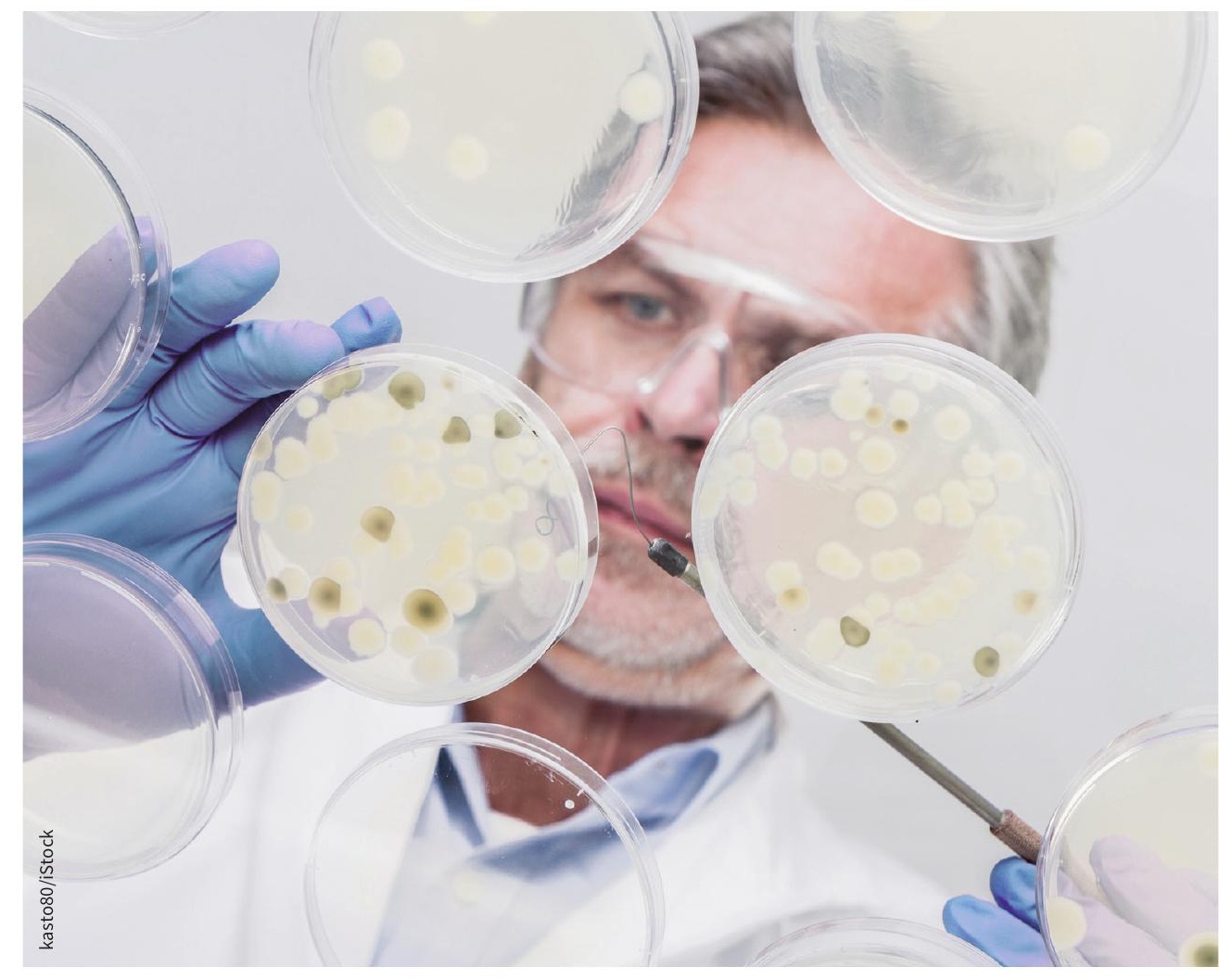

Funding agencies tend to favour older researchers, making it difficult for young investigators to further their careers and push scientific boundaries.

starting to look like a youngster's dream of playing in the National Hockey League," an early-career investigator from the Université de Montréal told the panel. The report recommended that the funding agencies boost support to young researchers and track their funding, "so that success rates can be adjusted as needed."

But Aidan Hollis, a University of Calgary economics professor, doesn't think the fix is that easy. "People tend to be a bit dismissive of things that are overambitious, which is probably a good sentiment to have generally, but it's problematic for scientific progress," he said.
Hollis pointed to the paper "Does science advance one funeral at a time?" The lead author, economist Pierre Azoulay of the Massachusetts Institute of Technology, led a team that tested the claim by Max Planck, the father of quantum mechanics, that a new scientific idea moves forward only after its opponents die. Identifying hundreds of American science superstars who died while still active, the team looked at what happened in their fields subsequently. Scientists who had collaborated with the superstars saw their publication and funding rates fall over the next five years, while scientists 
who had never collaborated with the stars began entering the stars' subfields, leading the team to conclude that eminent scientists "restrict the entry of new ideas and scholars into a field."

Nobel Prize winners Drs. Barry Marshall and Robin Warren encountered this, famously, in the 1980s, when they hypothesized, and later proved, that peptic ulceration is primarily an infectious disease. Marshall tried presenting their findings at a gastroenterology meeting in their native Australia, but his abstract was rejected; at the time, ulcers were believed to result from stress. The pair eventually published in The Lancet, but more than a decade passed before the medical community accepted that many patients with ulcers require antibiotics. Marshall later wore his rejections as a badge of honour, displaying them during talks.

The failures of the scientific funding and publishing system are no laughing matter to Aled Edwards, a molecular biologist and entrepreneur at the University of Toronto. At a recent meeting in Ottawa, Edwards showed that the most popular targets for genomic research in 2016 were nearly the same as in 1999, the year an international team first mapped the genetic code of a human chromosome. That means scientists are leaving much of the genome understudied, he said. "We're trying to fund innovation, but unfortunately we don't really get it."

The problem, said Edwards, is that it's risky to work on a less-studied gene. Since other labs aren't working on it, cell lines and reagents aren't readily available, "and by the time you've made all that, you've lost your grant." In addition, he said, findings about better-known genes are "far easier to publish."

To speed discoveries, he cofounded the Structural Genomics Consortium, comprising more than 300 scientists at universities in the Americas and Europe. Consortium members focus largely on genes or proteins the scientific community has ignored, using an open-access model of research, including electronic lab notebooks, so that their work can be followed in real time. And they don't file patents, instead placing everything in the public domain.

Despite choosing unpopular scientific targets, their unconventional model has brought in about $\$ 400$ million in industry and government support. Describing one molecule that has led to clinical trials for various forms of cancer, Edwards said he thought the consortium "probably shaved four years off the process" of drug development.

Azoulay suggested another idea: strengthening support for less established researchers by capping the amount of funding that goes to any single laboratory. But this has proven hard to enact. The US National Institutes of Health (NIH) implemented a cap in May 2017, limiting individual investigators to no more than the equivalent of three major grants at one time, but NIH leaders withdrew the cap within a month amid a backlash from "a small but very vocal segment," said Jon Lorsch, director of the National Institute for General Medical Sciences.

Lorsch has gathered data showing that the current system favours senior scientists. The agency spends over $40 \%$ of its monies on $10 \%$ of its most senior investigators. Many younger, early-career scientists are "right on the edge and unfortunately some of them do not wind up making it," he said. A committee on how best to support early- and mid-career investigators is scheduled to report in June to NIH director Dr. Francis Collins.

In Canada, CIHR cancelled a major initiative for young investigators last year. It had a policy reserving $15 \%$ of its longterm awards, called foundation grants, for early-career researchers. But last July the agency made the early-career group ineligible for foundation grants.

Instead, in the competition for shorter project grants, CIHR enacted a rule that assures higher success rates for the most junior applicants by matching the proportion of grants they receive to the proportion of young investigators in the applicant pool. In the most recent competition, the agency funded an additional 21 early-career investigators over those who would had been funded before the new rule took effect, according to Adrian Mota, CIHR director-general of operations support. "We're protecting them in a different way," he said.

But critics say CIHR sets too much money aside for established researchers through the foundation grants program. "What they've done now is made it worse for young investigators," said John Bergeron, an emeritus professor of medicine at McGill University. CIHR has formed a review committee charged with making recommendations "on the best way forward" for the foundation program.

Lee finally received a sizable grant in 2012. In 2015, he tested an experimental drug he hoped would "plug a hole" in the lungs by protecting endothelial cells, stopping lung blood vessels from leaking. After infecting mice with different forms of influenza, including the 2009 H1N1 strain, he gave mice the drug and found that over $80 \%$ survived, even if treated 72 hours after infection. That drug, designed by researchers at Toronto's Sunnybrook Research Institute, is still in early development, but Lee has now developed a zebrafish model of flu that's allowing his lab to screen thousands of compounds in the search for other promising anti-flu drug candidates.

Lack of funds early on may have delayed Lee's work, but in 2016 he won a Canada Research Chair with its promise of a decade of funding. When he gives talks, someone usually asks why no one had previously tested the idea of targeting lung endothelium. His typical response: "I wish you'd been evaluating the grant when it got rejected."

Miriam Shuchman, Toronto, Ont. 